\title{
Professionalism of China's football: League, Market and Transfer
}

\author{
Xiaoxue Liu ${ }^{1}$, Yanfen Zhang ${ }^{2}$, and Xuezhi $\mathrm{Ma}^{3}$ \\ ${ }^{1}$ Department of Physical Education, China University of Geosciences, Xueyuan Road, Haidian \\ District, Beijing, P. R. China \\ ${ }^{2}$ Department of Life Sciences; Xinxiang University, Xinxiang Henan province, Eastern Section of \\ Hua Lan Road, Hongqi District, Xinxiang City, Henan, China \\ ${ }^{3}$ Beijing Sport University Wushu School, Information Road, Haidian District, Beijing, China \\ xxliu8888@aliyun.com,1421185078@qq.com, malaoshide21@sohu.com
}

Keywords: Chinese Football, League, Market, Transfer, Soccer Teenager

Abstract: Research question: this article researches in the characteristics and analysis on the problems appearing during the process of Chinese football professionalism. Research methods: it adopts the methods of literature review, expert consultation and questionnaire survey to review and summarize the process of Chinese football professionalism (1992-2016) in four stages. Results and Findings: the article suggests that Chinese football professionalism is based on the league system, marketization and transfer mechanism is the motive force of football development, and the development of soccer teenagers is also very important. Implications: the article transmits the idea of marketizing football management system and its operation mechanism in which "League, Market and Transfer" should be the primary impetus for Chinese football.

\section{Introduction}

Throughout the process of Asian football professionalism, each country in East and West Asia has formed its own unique "professionalism mode”, Saudi Arabia hires qualified coaches, Iran introduces football talents, South Korea has been devoted to imitating the European strength-based style for years and Japan has adopted the club league match mode in recent years, all of which have largely improved the competitiveness of national football respectively. Although Asian football professionalism has achieved a rapid development by virtue of its strong economic strength, football match is an accretion-based culture which relies on long-time accumulation and team optimization to make a crucial leap and form a powerful impact. Therefore, the overall competitiveness of Asian football cannot meet people's expectation and to some degree, the excessive investment and expectation involved in Asian football professionalism should serve as the precious experience and lessons for the development of Chinese football professionalism. 


\section{The Process of Chinese Football Professionalism and Commercialization}

\subsection{The Beginning of Chinese Football Professionalism and Commercialization (1992-1993)}

In 1958, China returned to Federation Internationale de Football Association (FIFA). Initially, China adopted the non-marketized football match management system directly under control of the central government, rather than its professionalism and club system. But as it was developed out of nothing, China’s football won decent progress to certain extent (Chen Yazhong, 2017).

\subsection{The Initial Achievement Stage of Chinese Football Professionalism (1994-2003)}

On April 17, 1994, Marlboro Cup National Football League A was officially unveiled, representing the start of comprehensive football reform. From 1994 to 2003, from the debut in Chengdu stadium to the closing game in Shanghai, Chinese Football League A existed for only 10 years during which, according to rough statistics, around 130 professional clubs were involved in 3024 matches with 46.95 million spectators, creating annual revenue of over 700 million Yuan for the clubs. Till then, China has established a preliminary league system and Chinese football market gradually began to take shape, through which football has gained its social influence and become the national sport in terms of scale and influence, and there are more and more football clubs.

\subsection{The Dilemma Confronted by Chinese Football Professionalism and Commercialization (2004-2014)}

In 2004, Chinese football entered into super league stage. However, it didn't get off to a good start as league A did 10 years ago. According to the league work report, 132 Chinese Super League matches of 22 rounds in 2004 only attracted 1.45 million spectators with an average of 11,000 each match, down by 38\% compared with Chinese League One in 2003 and hit the record low of Chinese professional league. Besides, 130 million TV audiences also showed a 42\% decrease. Most sponsors claimed sharp withdrawal in capital because the estimated revenue of 130 million Yuan was far beyond reach while the actual revenue may be merely 70 million Yuan, reduced by $46 \%$. Therefore, Chinese Super League suffered huge losses in social effects and economic interest as well as public trust and image.

Early in 2004 when the Chinese Football Association Super League kicked off, the football market once revived, however, since the problems that Chinese football confronted have not been resolved totally, especially those involving the system; Chinese Football Association Super League was soon caught in a new crisis. Beijing Guoan Football Club went on strike on football match which contributed to a new round of football reform initiated by investors from seven football clubs led by Dalian Shied and Beijing Guoan, aiming at "separating government from enterprises, isolating management from administration”. Although Chinese Football Association finally decided to adopt a range of measures such as establishing Chinese Football Association Super League Co. Ltd, allowing enterprises to retain more profits, governing the league match environment and regulating football clubs, no substantive change appeared at last both in terms of its system and operation mechanism.

In 2005, Chinese Football Association Super League was not sponsored by any company. Therefore, CCTV did not transmit any match in three seasons from 2004 to 2006, resulting in a sharp drop of its commercial value. What were worse, under the faulty management and supervision system, there appeared massive rigged games, black whistles and gamble on games. Those well-renowned international referees, investors of professional football clubs and officials of local football associations were all involved in the vicious event of "cheating, gambling and black 
whistle”, giving rise to a plummet in the competitiveness of Chinese football and the National Team's slide in the rank list of both FIFA and Asia. That is simply to say that Chinese professional football league match not only failed to achieve the expected good results, but met more problems and worse performance.

\subsection{Chinese Football Back on the Path of Professionalism and Commercialism (2015-present)}

In October, 2014, Some Suggestions to Promote the Development of Sports Industry and Sports Consumption published by the State Council indicates that we should develop potential industries and by 2025, the total value of sports industry should have exceeded RMB 5 trillion (Yamamura E. 2015). With football, basketball and volleyball as the starting point, we should accelerate the development of team sports featuring wide popularity, intensified attention and large market space. Besides, the document also suggests that we should make a long-term development and field construction plan for the backwards football projects, especially promoting the development Football both at school and in the whole society.

On 26 January 2015, the State Council discussed and adopted the overall reform scheme on Chinese football. On 27 February, the comprehensive reform group of the central committee passed the scheme which proposes a "three-step" strategy, namely the short-term, mid-term and long-term object. During the short-term stage, the country should regulate the football management system, make the middle-and-long-term plan for football and create a new football management mode with Chinese characteristics. The mid-term object is to greatly increase the number of teenage football players and reach the Asia-leading level in both football competitiveness and professional league match organization. Besides, the national man's football team is supposed to stand out in Asia and woman's football team should go back among world-leading football powers. The long-term object is that China shall win the bid for the World Cup, man's team having access to the World Cup and Olympic Games. With these aims, Chinese football has returned on the path of professionalism and commercialism.

\section{Reflections on the Process of Chinese Football Professionalism}

\subsection{League Match System Being the Only Path for Chinese Football Professionalism}

The process of Asian football professionalism has proved that a perfect league system is the only path in this process. For example, Japan, learning from the successful experience of baseball, has made detailed rules and regulations for a number of problems including the competition system, agenda and field of professional league matches, the structure, scale, and ownership of football clubs, and football transfer, external aid and football market over 20 years of preparation. Therefore, Japan's football league match develops relatively smoothly, making football deeply rooted among the people. Meanwhile, the success of Japanese football league match has aroused attention from FIFA and it becomes the professional league match that attracts most advanced coaches and athletes in non-Europe areas. It is 25 years since the start of League A in China. However, it is quite worrying that while the system for football professionalism still needs improving people are anxious to seek quick success and instant benefits at the initial stage. The main manifestations are as follow: first, unreasonably high expectation encourages enterprises to largely invest in football industry, whereas massive investment will not bring about returns in a short period given the law of development for football professionalism; second, a lack of high-level talents results in the wallet of some members of political consultative conference expanding at an alarming rate, which aggravates the pressure of football clubs. The professional imperfections of football players contribute to a range of new problems in management. Moreover, "black whistles and rigged games" severely 
impede the process of Chinese football professionalism and the improvement of football competitiveness.

\subsection{Introducing Advanced Foreign Football Techniques and Forming Unique Technique Style with Chinese Characteristics Simultaneously}

Saudi Arabia, after learning Brazilian style for 30 years, developed into South American technique style featuring tactical techniques, finesse in football skills, short-passing infiltration and frontline breakthrough; South Korean football team has modeled after Europe and formed European Strength-based playing style (Frick Bernd, 2009) with simplified actions, violent tackling, excellent physical quality of players as well as vigor and vitality. In the World Cups that followed, football teams from Saudi, Korea, Iran and Japan, fearless to compete with world top teams, displayed their competitiveness and their individual style, whereas Chinese football with better humanity and culture background still cannot rush out of Asia and walk up to the world. Adopting improper method when learning from world major football powers may be one of the reasons contributing to this tragedy. In the mid-1950s, Chinese football team went to Hungary for two years of study, based on which its own technique style was formed, and the competitiveness of Chinese football was improved as well. Since then, dramatic changes took place in China. Chinese football learned techniques and experience from major football powers sequentially such as the Soviet Union, Brazil, Germany, Italy, Argentina and Britain. However, Chinese football did not seek in-depth experiences from any one of them. Such a learning method, isolated from Chinese football practice and the national condition and with a lack of profound analysis, would surely lead to a long-term uncertainty with regard to football techniques and style (Song Hengmao, 2011). Therefore, China is supposed to draw lessons from its own past to develop football in a sustainable way of learning from world major football powers while insisting on and giving full display of its own advantages.

We can know that the transfer of Chinese football players is becoming more and more frequent, and it shows that the professionalization of Chinese football is developing in a benign direction.

Facts show that the professionalism process of Chinese football is closely related to the performance of Chinese football clubs in AFC Champions League. In 2003 and 2004, the professional league developed smoothly with satisfying achievements. However, due to the explosion of problems in football management system, the overuse of "government management" in the league's popularization process, together with scandals such as football fraud, black whistle and football gambling, Chinese football remained unchanged for around ten years. Until 2013 and 2015 when the State Council initiated and approved "The Overall Reform Scheme on Chinese Football”, Chinese football broke away from the government-dominant system to implement market-based operation mode, accelerating its development in professionalism process.

\subsection{The Development and Popularization of Teenage Football Playing a Critical Role in the Process of Chinese Football Professionalism}

It has been found that teenage football players have competitive edge over adult players in terms of receptivity and learning ability. Meanwhile, the process of Asian football professionalism shows that the leading football countries in Asia, on the one hand, pay much attention to learning from foreign countries with successful experience in this field. They not only introduce excellent football players to join their team, but recommend their talents to play in European football clubs. On the other hand, they put a large amount of time and energy in cultivating teenage football players, which lays a solid foundation for the improvement of football performance. In South Korea (Cronin, Doyle, and Callaghan, 2008), a country with a good football tradition, an increasing number of teenagers are willing to participate in football training in different schools at different levels or in 
clubs. More and more Saudi Arabian teenagers are active in registering as a member of the football clubs, which is beneficial for continuous development and cultivation of football players at younger generation, helping make preparations for frontline matches; and the popularization and advocation of teenage football is favorable for the long-term development of national football sport. In Japan, football and other sports receive much attention from school leaders and teachers and support from parents. Hence, students are highly active in taking part in such activities. The football teaching and training at school are mainly performed in games for the sake of cultivating students' interests and allowing them to exert their potential freely. With great interest, football coach teaches students the basic football techniques such as kicking, taking a pass, ball handing, scrambling for ball, etc. After mastering the basic knowledge and techniques, students are required to compete in matches to experience the genuine sports. More often than not, teachers of all subjects may participate in the matches. At schools especially at primary schools, mothers of students in football training often serve as cheering squad and organizers of football clubs.

\subsection{Focusing on the Introduction of Advanced Techniques as well as Modern Football Philosophy}

Foreign football players and coaches are introduced to promote the development of football within the country. Currently, China mainly focuses on direct introduction and immediate benefits, lacking culture tolerance and equal treatment toward foreign players. As a result, the long-term indirect influence produced along with the introduction of foreign players, especially the introduction and integration of modern football philosophies, is not paid much attention to. The way of importing excellent football players to play for China can hardly improve the competitiveness of Chinese football.

There is no denying that some senior football coaches at home are against the practice of recruiting foreign coaches with high salary. However, if we identify with and absorb the modern football philosophies brought along with foreign coaches and integrate them in light with our own characteristics; it's conducive to the process of Chinese football professionalism and improvement of competitiveness. Emphasizing and encouraging our own talents to study further at football clubs in leading football powers and introducing foreign players to improve national competitiveness are the major ways for player training in Asian countries.

In 1954, a team was sent to Hungary where they got the coach Joseph, the first foreign coach for China, under whose leadership, the team achieved great progress. In 1992, Klaus Schlappner was invited from Germany to be the chief coach for Chinese football team which later won the third place in the 10th Asian Cup. However, the team failed to get the qualification to compete in the World Cup final in 1993, and since then Schlappner has faded out in Chinese football circle. In 1998, the English man Bobby Houghton took over Chinese football team which won the bronze medal in the 1998 Asian Games, whereas the failure of the National Olympic Team in the Asian preliminaries directly resulted in his quit. In 2000, Bora Milutinovic from the former Yugoslavia took over the duty and Chinese team won the fourth place in the Asian Cup. In 2001, Chinese team succeeded in the World Cup qualifier competing for top 10, which realized the dream of Chinese football fans. Milutinovic had to resign from his post after 2002 FIFA World Cup Korea/ Japan where Chinese team didn't score any goal but lost nine goals in three games. At the end of 2002, Adrianus Haan from Holland became the new chief coach and guided Chinese team to win the silver medal in the 2004 Asian Cup in China. Adrianus Haan was also forced to quit after the failure in the Asian qualifier of 2004 World Cup. From Oct. 2006 to Jul. 2008, Vlado Petrovic and Ratomir Dujkovic from Serbia acted as the executive coach and chief coach for the National Olympic Team respectively. From Aug. 2011, José Camacho undertook the duty of chief coach for Chinese Men's 
National Football Team and broke the contract in Jun. 2013. On Feb. 28 2014, Chinese Football Association held a press conference in Qingyuan, Guangzhou for the announcement of Alain Perrin as the new chief coach for man's team. On Jan. 7 2016, he resigned from his post.

\section{The Professionalism Process of Chinese Football Falls Into Four Stages}

The preparatory stage (1992-1993). In 1992, national football working conference was held in Hongshankou in the suburbs of Beijing, namely "Hongshankou Conference".

The stage of initial achievements (1994-2003). On April 17, 1994, Marlboro Cup National Football League A was officially unveiled, representing the start of comprehensive football reform and displaying the initial achievements of China's ten years' of efforts to professionalize its football games.

The slow development stage (2004-2014). In 2004, Chinese football entered into the stage of club system-based super league.

The stage of fully marketized operation mechanism (2015-present). In this period the State Council discussed and adopted The Overall Reform Scheme on Chinese football.

Through the comparison between the professionalism process of Chinese football and that of other Asian countries, it is not difficult to find that there is a long way to go for Chinese football before its fully professionalized.

First, football league is the producer of elite players for a country as well as the major embodiment of its football competitiveness. Therefore, it is of great urgency for China to improve its league system, actively expand market for football and promote and its related industry, and establish a dynamic talent flow mechanism for the healthy and sustainable development in this field. Furthermore, China should introduce outstanding football players and coaches worldwide, and form a football technique style with Chinese characteristics so as to improve the overall competitiveness of Chinese football.

Second, teenage football is the future for a country's football industry. As Chinese football is stuck in low ebb, China should strive to develop teenage football tremendously based on a scientifically reasonable development plan. China should support teenage football both financially and conceptually, modestly absorb advanced experience from foreign countries, enabling Chinese football professionalism to keep up with international trends.

Third, the reform of Chinese football is influenced by two different systems, namely planned economic system and market economic system. If the latter is implemented, football clubs will be operated in line with market rules and the professionalism reform is surely to bear fruits. Consequently, the core of the professionalism reform of Chinese football lies in the reform of its management system. In this sense, it's high time for Chinese football to transit from "governmentmanagement system" to "market system", which is the key for swifter, healthier and better development of Chinese football professionalism.

\section{Acknowledgements}

This paper is supported by "Project of the humanities and social sciences research program of the Ministry of education of China" (15YJA890016), Basic scientific research projects in Chinese Universities (2-9-2015-417) and China University of Geosciences (Beijing) key project of teaching reform (JGZHD201711).

\section{References}

[1] Cronin, Doyle and Callaghan, 2008. Foreign Fields and Foreigners on the Field: Irish Sport, Inclusion and 
Assimilation,” International Journal of the History of Sport. 8, pp.1010-1030.

[2] Frick Bernd, 2009. Globalization and Factor Mobility: The Impact of the "Bosman-Ruling” $m$ on Player Migration in Professional Soccer, Journal of Sports Economics.10, pp.88-106.

[3] Hengmao Song, 2011. Reflecting the Reasons of Chinese Football Backwardness in the View of Training, Advances in Education Research.2, pp. 481-484.

[4] Yamamura E. 2015. Wage Disparity and Team Performance in the Process of Industry Development: Evidence from Japan's Professional Football League, Journal of Sports Economics. 16, pp. 214-223.

[5] Yazhong Chen, 2017. Analysis on the Features and Problems of Professional Football Club Regional Distribution in China, Journal of Chengdu Sport University. 3, pp.57-61. 